\title{
Higher Depression of Patients with Alzheimer's Disease During than Before the Lockdown
}

\author{
Mohamad El Haj a,b,c,* Ahmed A. Moustafa ${ }^{\mathrm{d}, \mathrm{e}}$ and Karim Gallouj ${ }^{\mathrm{b}}$ \\ ${ }^{a}$ Laboratoire de Psychologie des Pays de la Loire (LPPL - EA 4638), Nantes Université, University of Angers, \\ Nantes, France \\ ${ }^{\mathrm{b}}$ Unité de Gériatrie, Centre Hospitalier de Tourcoing, Tourcoing, France \\ ${ }^{\mathrm{c}}$ Institut Universitaire de France, Paris, France \\ ${ }^{\mathrm{d}}$ School of Psychology \& Marcs Institute for Brain and Behaviour, University of Western Sydney, Sydney, Australia \\ e Department of Human Anatomy and Physiology, Faculty of Health Sciences, University of Johannesburg, \\ Johannesburg, South Africa
}

Accepted 2 April 2021

Pre-press 21 April 2021

\begin{abstract}
We assessed depression in 72 patients with Alzheimer's disease (AD) who live in retirement homes during the COVID-19-related lockdown. We invited caregivers of 72 patients with $\mathrm{AD}$ who live in retirement homes to rate depression in the patients both before and during the lockdown. Analysis demonstrated increased depression in the patients during the lockdown. We attribute this increased depression to the restrictive measures on activities, visits, and physical contact between patients with $\mathrm{AD}$ and family members during the lockdown.
\end{abstract}

Keywords: Alzheimer's disease, COVID-19, depression, lockdown, social isolation

\section{INTRODUCTION}

While Alzheimer's disease (AD) is primarily associated with cognitive decline [1,2], it is also characterized by neuropsychiatric symptoms, especially depression [3, 4]. During the course of AD, nearly up to $50 \%$ of patients experience some degree of depression [5] and $20 \%$ to $30 \%$ of patients meet criteria for major depressive disorder during the course of the disease [6, 7]. Depression in AD can be attributed to iatrogenic factors, especially to medications including benzodiazepines, corticosteroids, beta-blockers

\footnotetext{
${ }^{*}$ Correspondence to: Mohamad El Haj, Faculté de Psychologie, LPPL - Laboratoire de Psychologie des Pays de la Loire, Université de Nantes, Chemin de la Censive du Tertre, BP 81227, 44312 Nantes Cedex 3, France. E-mail: mohamad.elhaj@univ-nantes.fr.
}

[8], dopamine agonists, anticonvulsants, and anticholinergic [8]. Other risk factors for the development of depression in $\mathrm{AD}$ are family history of depression $[9,10]$, and having the epsilon4 allele of the APOE4 gene, which is among the main genetic risk factors for sporadic AD [11, 12]. Depression in AD can lead to functional decline and behavioral disorders [9], hospitalization [13], and even mortality [14].

Depression in patients with $\mathrm{AD}$, especially those living in retirement homes, has likely increased during lockdown that was implemented to cope with the COVID-19 pandemic. With the spread of COVID19 , many countries have implemented lockdowns to keep citizens physically distant from each other. In France, a strict lockdown was implemented from March 16, 2020 to May 11, 2020, followed by some 
freedom of movement from May 12, 2020 to October 29, 2020. Another strict lockdown was implemented from October 30, 2020 and was lifted on November 27, 2020. While the lockdown slowed to spread of the infection, it might have led to severe psychological drawbacks, especially for residents of retirement homes who suffered more severe social distancing than most of the population. To cope with COVID19 and limit its spread among residents, retirement homes have been obliged to reduce physical contact between residents and families and friends and, in several cases, even between residents or between residents and caregivers. While these measures have served to limit infections, these preventive measures have forced retirement homes to reduce physical contact between residents and families as well as several inner and outer activities. These preventive measures have decreased wellbeing and mental health in patients with $\mathrm{AD}$ who live in retirement homes, as illustrated below.

In this study, we hypothesize that restrictive measures implemented by retirement homes to contain the spread of COVID-19 will decrease depression in residents with $\mathrm{AD}$. This assumption was based on a study by El Haj et al. [15] who invited patients with mild $\mathrm{AD}$ living in retirement homes to rate their depression during the lockdown, as well as to rate their depression before the lockdown. Results demonstrated increased depression during the lockdown. While the study of El Haj et al. [15] provides the first evidence of the effects of lockdown on depression in patients with mild $\mathrm{AD}$ who live in retirement homes, one shortcoming of this study is that depression was self-evaluated by the patients. In other words, the patients had to introspect into their own subjective state to remember how they felt several weeks prior to the lockdown. Because AD is mainly characterized by memory decline, the depression rating in the study of El Haj et al. [15] may be hampered by the recall bias, that is, by the decreased ability of patients to remember how they felt before the assessment. Furthermore, the ability of patients with AD to rate their own depression can be hampered by their lack of insight or anosognosia [16-21]. Thus, recall bias and anosognosia might hamper the ability of patients with $\mathrm{AD}$ to estimate their own depression during and before the lockdown, as assessed in the study by El Haj et al. [15].

To address the self-assessment limitation of the study by El Haj et al. [15], in the current study, we assessed depression in patients with $\mathrm{AD}$ who live in retirement homes during the lockdown by inviting caregivers to rate the patients' depression. More specifically, we invited caregivers to rate depression in patients with $\mathrm{AD}$ during the lockdown, and before the lockdown as a baseline. We expected increased depression in the patients during, compared with before, the lockdown.

\section{METHODS}

\section{Participants}

The study included seventy-two participants with a clinical diagnosis of probable AD (43 women and 29 men; $M$ age $=72.94$ years, $S D=7.11 ; M$ years of formal education $=9.12, S D=2.30$ ), who voluntarily participated in the study. All participants provided their consent to participate, and the procedures were designed and conducted in accordance with the Declaration of Helsinki. We recruited the participants by contacting psychologists and nurses who work in retirement homes in France, either directly or through social networks. We invited these on-site caregivers to provide historical information about the participants and to administer study procedures. Regarding diagnosis, we invited the on-site caregivers to verify, in the medical records, that a diagnosis of probable $\mathrm{AD}$ dementia was made by a neurologist or geriatrician according to clinical criteria developed by the National Institute on Aging and the Alzheimer's Association criteria for probable Alzheimer's disease [1]. We also invited on-site caregivers ( $M$ age $=36.11$ years, $S D=10.46$ ) to provide data regarding general cognitive functioning of the patients, so as to assess (as illustrated in the Results section) potential relationship between depression and general cognitive functioning. More specifically, we invited on-site caregivers to provide data regarding scores on the Mini-Mental State Exam [22] within three months before the study to provide an recent assessment of their cognitive status. The mean score of the participants on the Mini-Mental State Exam was 19.03 out of the maximum score of 30 points $(S D=3.03)$. We did not ask on-site caregivers to repeat the administration of the Mini-Mental State Exam because of their increased workload during the lockdown, and during the COVID-19 crisis in general. For the same reason, we did not ask the caregivers to perform other cognitive or clinical tests.

We defined the sample size as the number of patients (and on-site caregivers) who were willing to participate during the lockdown (May 12, 2020 to November 27,2020$)$. The sample size $(n=72)$ 
fairly fits $G^{*}$ Power analysis [23] in which we calculated sample size for Wilcoxin tests (as required to test our hypothesis, see the results section) based on $95 \%$ power, an estimated probability of making TypeI error of 0.05 , and a medium effect size of 0.50 [24]. This analysis suggested that only 47 participants would be necessary to obtain sufficient statistical power.

\section{Procedures}

During the lockdown (May 12, 2020 to November 27,2020 ), we invited the on-site caregivers to rate depression in patients with $\mathrm{AD}$ during and before the lockdown. More specifically, we invited the caregivers to rate the severity of depression of patients using a four-point scale: $0=$ not at all present, $1=$ slightly depressed, $2=$ moderately depressed, $3=$ very depressed. We provided caregivers with the same instruction "we invite you to report the levels of depression, if any, in the patient during the lockdown and before the lockdown, as implemented in the retirement home where you work. We invite you to regard depression in terms of state of low mood, persistent sadness, loss of interest in daily activities, as well as lack of energy and loss of appetite in the patient". We provided these instructions by phone and instructed caregivers to rate depression and provide us with these scores later by phone or email.

\section{Statistical analysis}

We compared means on the two ratings of depression (i.e., before versus during the lockdown). We used non-parametric tests (i.e., Wilcoxon signed rank tests) due to the scale nature of the variables and their abnormal distribution.

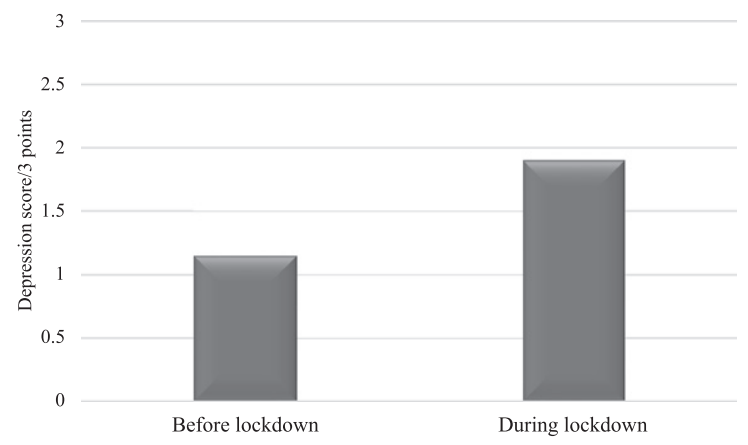

Fig. 1. Mean scores of depression in $\mathrm{AD}$ patients before and during the lockdown.

\section{RESULTS}

\section{Higher depression during than before the} lockdown

As illustrated in Fig. 1, patients demonstrated higher depression during (Median $=2.00, S D=1.08)$ than before (Median $=1.00, S D=2.00)$ the COVID19 crisis $(Z=-4.39, p<0.001$, Cohen's $d=1.21)$.

\section{No significant correlations between depression and cognitive functioning}

Spearman's correlation analysis demonstrated no significant correlations between general cognitive functioning (i.e., performances on the Mini-Mental State Exam) and depression before $(r=-0.15$, $p=0.21$, CI $[-0.37,0.084])$, or during the lockdown $(r=-0.10, p=0.40, \mathrm{CI}[-0.32,0.13])$. Significant correlations were observed between depression before and during the lockdown $(r=0.37, p=0.001, \mathrm{CI}$ $[0.15,0.55])$.

\section{DISCUSSION}

We assessed the effects of lockdown on depression, as reported by caregivers, in patients with $\mathrm{AD}$ who live in retirement homes. Analysis demonstrated higher depression during than before the lockdown in patients with AD.

The increased depression in $\mathrm{AD}$ patients with who live in retirement homes during the lockdown, as observed in our study, can be attributed to the restrictive measures that were implemented to contain the spread of COVID-19. These restrictive measures have decreased physical interaction between the patients and their family members. Although families were sometimes allowed to visit patients in geriatric facilities during the lockdown, visits occurred in a restricted environment, generally prohibiting physical contact and long visits, which might increase depression in patients who live in retirement homes. Furthermore, while many patients with AD were keeping contact with family members via virtual communication tools, this technology was not available to all patients. Communication through this technology can be hindered by unfamiliarity of some patients with this technology, and, critically, by the cognitive and sensory impairments in AD in general. This technology can be also considered as a modest substitute for physical contact as needed by patients with $\mathrm{AD}$ [25]. Besides the restrictions on 
physical contact with family members during the lockdown, retirement homes have had to implement other restrictions to cope with the spread of coronavirus. These restrictions included suspension of activities considered as non-essential, such as nonessential personnel (e.g., hairdressers), group activities, and even communal dining. Another factor that might contribute to depression of residents is the decreased contact with caregivers who, despite their efforts to provide the best care, have been dealing with an increased workload, shortages in equipment and supplies, and increased postmortem care. Research has even demonstrated increased burnout in geriatric healthcare workers during the lockdown [26]. Taken together, the restrictive measures implemented during the lockdown to contain the spread of COVID-19 have probably increased depression in patients with $\mathrm{AD}$ who lived in retirement homes.

The increased depression during lockdown in patients with $\mathrm{AD}$ living in retirement homes may be more influenced by the social restrictions than by the cognitive decline in AD. This assumption can be supported by the lack of significant correlations between scores on the Mini-Mental State Examination and depression, as observed in our study. Thus, depression in patients with $\mathrm{AD}$, at least those living in retirement homes, during the lockdown seem to be slightly or not at all influenced by cognitive dysfunction. However, regardless of its underlying mechanisms, patients' depression as observed in our study should be addressed to improve the patients' mental health. Interventions including psychological therapies, animal-assisted therapies, befriending interventions, and leisure/skill development interventions can be considered, during and after the lockdown. Furthermore, retirement homes can consider creating positions like "visitation coordinator" who guides the visits, screens the visitors, and informs them regarding precautions and risks during the lockdown.

By inviting caregivers to assess depression in patients with $\mathrm{AD}$, our study contributes to research demonstrating decreased mental health in these patients during the lockdown [27-31]. More specifically, our study addresses the shortcoming of previous research on depression in patients with $\mathrm{AD}$ who live in retirement homes during the lockdown as, in this research, patients were invited to rate their own depression [15]. While it may allow to understand how the patients experience their own depression, this assessment is hampered by the limited ability of patients to gain insight into their own mental and cognitive states, that is, possibly due to anosognosia. Our study addresses this limitation by inviting caregivers to rate the patients' depression. By doing this, our study provides evidence to the assumption that lockdown has increased depression in patients with $\mathrm{AD}$ who live in retirement homes.

One shortcoming of our study is that we invited caregivers to rate the severity of depression using only one item. In other words, our study did not include a comprehensive assessment of depression or even a short assessment of anxiety. However, due to the exceptional complexity of the lockdown (e.g., patients were not always accessible). Another limitation may be lack of a control group including patients with $\mathrm{AD}$ living at home during the COVID19 crisis, or even patients with neurodegenerative diseases other than AD. Also, because caregivers were probably under considerable stress during the crisis [26], this might influence their rating of the patients' depression (e.g., a recall bias regrading patients' depression before the crisis).

Because of their functional and cognitive decline, patients with $\mathrm{AD}$ are vulnerable, and this has been especially true during the COVID-19 crisis. While this crisis has significantly turned our daily lives upside down, this impact is significantly pronounced in patients with $\mathrm{AD}$, especially those living in retirement homes. Because patients with AD have a significantly higher risk of COVID-19 infection, retirement homes were forced to implement strict restrictive measures. However, and as demonstrated by our study, these restrictive measures have increased depression and, consequently, decreased mental health and wellbeing of patients.

\section{ACKNOWLEDGMENTS}

The authors would like to thank the patients for their generous participation as well as the caregivers who, despite the increased workload during the COVID crisis, have dedicated their time to the study. Dr. El Haj was supported by the LABEX (excellence laboratory, program investment for the future) DISTALZ (Development of Innovative Strategies for a Transdisciplinary Approach to Alzheimer Disease) and the EU Interreg CASCADE 2 Seas Programme 2014-2020 (co-funded by the European Regional Development Fund).

Authors' disclosures available online (https:// www.j-alz.com/manuscript-disclosures/21-0190r2). 


\section{REFERENCES}

[1] McKhann G, Knopman DS, Chertkow H, Hyman BT, Jack CR, Jr., Kawas CH, Klunk WE, Koroshetz WJ, Manly JJ, Mayeux R, Mohs RC, Morris JC, Rossor MN, Scheltens P, Carrillo MC, Thies B, Weintraub S, Phelps $\mathrm{CH}$ (2011) The diagnosis of dementia due to Alzheimer's disease: Recommendations from the National Institute on Aging-Alzheimer's Association workgroups on diagnostic guidelines for Alzheimer's disease. Alzheimers Dement 7, 263-269.

[2] El Haj M, Antoine P, Amouyel P, Lambert JC, Pasquier F, Kapogiannis D (2016) Apolipoprotein E (APOE) epsilon4 and episodic memory decline in Alzheimer's disease: A review. Ageing Res Rev 27, 15-22.

[3] Chi S, Yu JT, Tan MS, Tan L (2014) Depression in Alzheimer's disease: Epidemiology, mechanisms, and management. J Alzheimers Dis 42, 739-755.

[4] Gormley N, Rizwan MR (1998) Prevalence and clinical correlates of psychotic symptoms in Alzheimer's disease. Int $J$ Geriatr Psychiatry 13, 410-414.

[5] Starkstein SE, Jorge R, Mizrahi R, Robinson RG (2005) The construct of minor and major depression in Alzheimer's disease. Am J Psychiatry 162, 2086-2093.

[6] Enache D, Winblad B, Aarsland D (2011) Depression in dementia: Epidemiology, mechanisms, and treatment. Curr Opin Psychiatry 24, 461-472.

[7] Ballard C, Bannister C, Solis M, Oyebode F, Wilcock G (1996) The prevalence, associations and symptoms of depression amongst dementia sufferers. J Affect Disord 36, 135-144.

[8] Burke AD, Goldfarb D, Bollam P, Khokher S (2019) Diagnosing and treating depression in patients with Alzheimer's disease. Neurol Ther 8, 325-350.

[9] Lyketsos CG, Olin J (2002) Depression in Alzheimer's disease: Overview and treatment. Biol Psychiatry 52, 243-252.

[10] Rapp MA, Schnaider-Beeri M, Grossman HT, Sano M, Perl DP, Purohit DP, Gorman JM, Haroutunian V (2006) Increased hippocampal plaques and tangles in patients with Alzheimer disease with a lifetime history of major depression. Arch Gen Psychiatry 63, 161-167.

[11] Krishnan KR, Tupler LA, Ritchie JC, Jr., McDonald WM, Knight DL, Nemeroff CB, Carroll BJ (1996) Apolipoprotein E-epsilon 4 frequency in geriatric depression. Biol Psychiatry 40, 69-71.

[12] Qiu WQ, Zhu H, Dean M, Liu Z, Vu L, Fan G, Li H, Mwamburi M, Steffens DC, Au R (2016) Amyloidassociated depression and ApoE4 allele: Longitudinal follow-up for the development of Alzheimer's disease. Int J Geriatr Psychiatry 31, 316-322.

[13] Gaugler JE, Yu F, Krichbaum K, Wyman JF (2009) Predictors of nursing home admission for persons with dementia. Med Care 47, 191-198.

[14] Suh GH, Kil Yeon B, Shah A, Lee JY (2005) Mortality in Alzheimer's disease: A comparative prospective Korean study in the community and nursing homes. Int J Geriatr Psychiatry 20, 26-34.

[15] El Haj M, Altintas E, Chapelet G, Kapogiannis D, Gallouj K (2020) High depression and anxiety in people with Alzheimer's disease living in retirement homes during the Covid-19 crisis. Psychiatry Res 291, 113294.

[16] Grut M, Jorm AF, Fratiglioni L, Forsell Y, Viitanen M, Winblad B (1993) Memory complaints of elderly people in a population survey: Variation according to dementia stage and depression. J Am Geriatr Soc 41, 1295-1300.
[17] McGlynn SM, Schacter DL (1989) Unawareness of deficits in neuropsychological syndromes. J Clin Exp Neuropsychol 11, 143-205.

[18] Agnew SK, Morris RG (1998) The heterogeneity of anosognosia for memory impairment in Alzheimer's disease: A review of the literature and a proposed model. Aging Mental Health 2, 7-19.

[19] Mograbi DC, Brown RG, Morris RG (2009) Anosognosia in Alzheimer's disease - The petrified self. Conscious Cogn 18, 989-1003.

[20] Morris RG, Mograbi DC (2013) Anosognosia, autobiographical memory and self knowledge in Alzheimer's disease. Cortex 49, 1553-1565.

[21] Mayelle A, El Haj M, Antoine P (2019) Awareness of self and disease assessment: Development and validation of a subjective measure in people with Alzheimer's disease. $J$ Alzheimers Dis 71, 841-850.

[22] Folstein MF, Folstein SE, McHugh PR (1975) "Mini-mental state". A practical method for grading the cognitive state of patients for the clinician. J Psychiatr Res 12, 189-198.

[23] Faul F, Erdfelder E, Lang AG, Buchner A (2007) G*Power 3: A flexible statistical power analysis program for the social, behavioral, and biomedical sciences. Behav Res Methods 39, 175-191.

[24] Cohen J (1992) Statistical power analysis. Curr Dir Psychol Sci 1, 98-101.

[25] Gleeson M, Timmins F (2004) Touch: A fundamental aspect of communication with older people experiencing dementia. Nurs Older People 16, 18-21.

[26] El Haj M, Allain P, Annweiler C, Boutoleau-Bretonnière C, Chapelet G, Gallouj K, Kapogiannis D, Roche J, Boudoukha $\mathrm{AH}$ (2020) Burnout of healthcare workers in acute care geriatric facilities during the COVID-19 crisis: An online-based study. J Alzheimers Dis 78, 847-852.

[27] Giebel C, Cannon J, Hanna K, Butchard S, Eley R, Gaughan A, Komuravelli A, Shenton J, Callaghan S, Tetlow H, Limbert S, Whittington R, Rogers C, Rajagopal M, Ward K, Shaw L, Corcoran R, Bennett K, Gabbay M (2020) Impact of COVID-19 related social support service closures on people with dementia and unpaid carers: A qualitative study. Aging Ment Health, doi: 10.1080/13607863.2020.1822292

[28] Verbeek H, Gerritsen DL, Backhaus R, de Boer BS, Koopmans R, Hamers JPH (2020) Allowing visitors back in the nursing home during the COVID-19 crisis: A Dutch national study into first experiences and impact on well-being. $J \mathrm{Am}$ Med Dir Assoc 21, 900-904.

[29] Van der Roest HG, Prins M, van der Velden C, Steinmetz S, Stolte E, van Tilburg TG, de Vries DH (2020) The impact of COVID-19 measures on well-being of older long-term care facility residents in the Netherlands. J Am Med Direct Assoc 21, 1569-1570.

[30] Boutoleau-Bretonnière C, Pouclet-Courtemanche H, Gillet A, Bernard A, Deruet AL, Gouraud I, Mazoue A, Lamy E, Rocher L, Kapogiannis D, El Haj M (2020) The effects of confinement on neuropsychiatric symptoms in Alzheimer's disease during the COVID-19 crisis. J Alzheimers Dis 76, 41-47.

[31] El Haj M, Larøi F, Gallouj K (2020) Hallucinations in a patient with Alzheimer's disease during the COVID-19 crisis: A case study. J Alzheimers Dis Rep 4, 455-458. 